\title{
Modeling and simulation of hybrid SOFC-GT systems for Distributed Generation
}

\author{
C. Boccaletti, G. Fabbri, O. Riot, E. Santini \\ Department of Electrical Engineering \\ University of Rome "La Sapienza" \\ Via Eudossiana 18, 00184 Rome, Italy \\ Tel. +3906 44585762, Fax +39064883235 \\ e-mail: chiara.boccaletti@uniroma1.it; gianluca.fabbri@uniroma1.it
}

\begin{abstract}
This paper focuses on the modelling and simulation of Solid Oxide Fuel Cell (SOFC) and Gas Turbine (GT) hybrid systems for Distributed Generation. Independent dynamic models of the main components of the systems have been realized and implemented in the Matlab-Simulink ${ }^{(}$environment. The models have been used to simulate the behaviour of two plant configurations. Control methodologies have been analyzed and numerical results are provided.
\end{abstract}

\section{Key words}

Fuel Cell, Gas Turbine, Microturbine, Distribuited Generation, Modeling

\section{Introduction}

Based on previous modelling work on integrated hybrid systems [1-4], this paper focuses on the analysis of a particular configuration of these systems including Solid Oxide Fuel Cells (SOFCs) and Gas Turbines (GTs). An integrated hybrid system consists of a combination of two or more power generation technologies to make the best use of their operating characteristics and to obtain higher efficiencies than from a single power source. The Distributed Generation (DG) represents an important integration to the centralized electrical power generation and the extent of its application in a variety of types and capacities is becoming larger and larger. units are two types of technologies whose However, the performance of small distributed units such as those based on Fuel Cells (FCs) and microturbines - both for stand-alone applications and within a network - still need in-depth investigation. The microturbines have been known for a long time as reliable main or back-up power systems in a wide range of applications. FCs are also promising units, with many advantages like high efficiency, low emissions and the possibility of cogeneration. Thus, there is an increasing interest in integrated power plant systems involving both FCs and GTs (IFCGT). FCs are a promising approach to high-efficiency power generation, as they directly convert chemical energy to electric work. They complement heat engines and can reduce the dependence on fossil fuels and therefore have significant environmental implications. Particularly, SOFCs are expected to be around 50-60\% efficient in converting fuel to electricity and in cogeneration applications. Overall fuel use efficiencies can be as high as $85 \%$.
Owing to their attractive characteristics FCs are recognized as one of the most promising technologies to meet the future power generation requirements and likely to be widely used for the production of stationary electric energy.

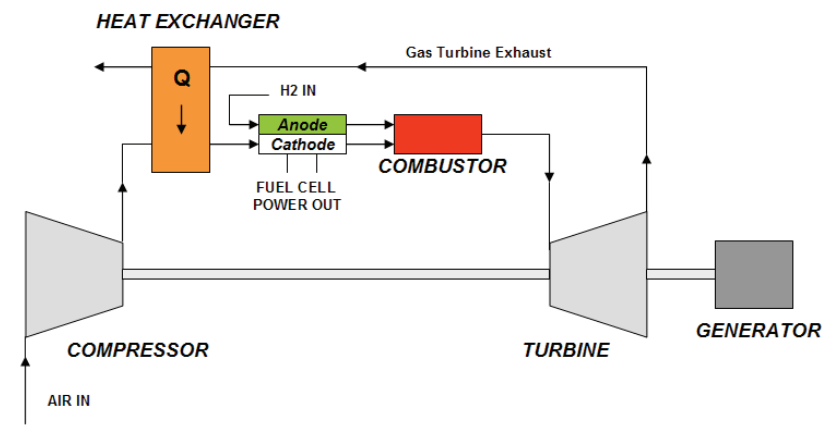

Fig. 1. Main components of an IFCGT system.

FC based power systems present a wide range of challenging problems for control and system integration. Complex system configurations and interactive subsystems lead to intricate transient dynamics and difficult control tasks. Recent development in system modeling, control analysis and system optimization allow us to achieve system performance improvements and enhancements. In an IFCGT plant a high temperature FC and a GT are used to achieve higher overall performance and efficiency than a single mode power plant. Due to the high temperature of the FC exhaust gas, heat can be recovered to supply a gas turbine producing additional power. In order to analyse the behaviour of the IFCGT plant, a simulation tool is needed to characterize the dynamics of the integrated system. Such a tool can be an essential first step also for the development and design of the control methodologies.

\section{Modelling of the proposed system}

Independent modular dynamic models of the main components of a IFCGT system have been developed by the authors, allowing both steady state and dynamic analyses. The models have been built in state-space format and independently tested and validated with GT data from literature and with FC data provided by an Italian research company, showing a good agreement with the experimental results. The models can be arranged into 
any configuration of a combined cycle. In Fig. 1 the main elements of the system are shown. They are:

\section{FC stack voltage \\ 2. Gas Turbine \\ 3. Compressor \\ 4. Combustor \\ 5. Heat Exchanger \\ 6. Generator}

In the following paragraphs the models of the FC stack voltage and of the GT will be described together with the control system. The models of other components, object of previous work, can be found in [5]-[6].

\section{Modelling of Micro-Turbines}

Fig. 2 shows the configuration used to build the microturbine dynamic model. Micro-turbines are small highspeed gas turbines. The three main parts are compressor, combustor, and the turbine. The compressor is used to pressurize the air before entering the combustor. Injected fuel is mixed with the compressed air in the combustor and the mixture is ignited. The mechanical energy is produced when the hot combustion gases flow and expand through the turbine. The turbine drives a permanent magnet synchronous generator (PMSG) connected to its shaft without gearbox. A part of the power produced in the turbine is utilized for driving the air compressor while the rest is converted to electricity in the PMSG.

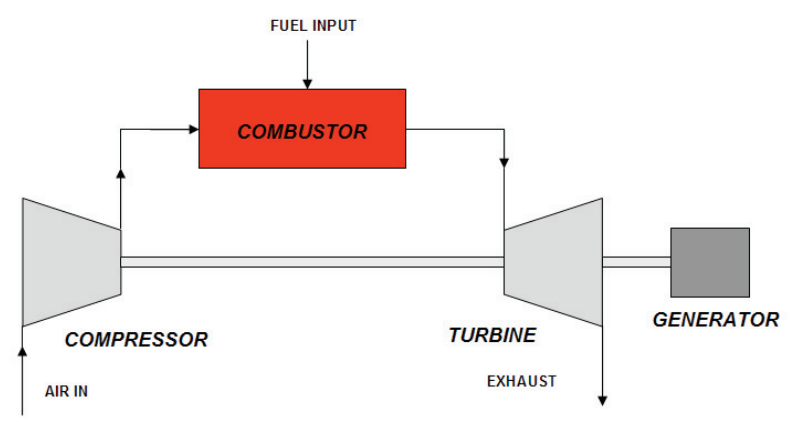

Fig. 2. Gas Turbine configuration

The turbine model is needed to simulate the torque transmitted to the compressor and the generator as well as to determine the portion of the overall gas turbine power. Torque is generated in the turbine when the working fluid expands and exerts a force on the turbine blades. The working fluid enters the turbine stator with velocity $C T 1$ and exits with velocity CT2. When the fluid passes through the turbine rotor stage, the change in direction of the fluid to $C T 3$ results in a force on the rotor, which provides the torque to the compressor and the generator and rotates the rotor with a velocity $U$. Unlike the compressor model, turbines are relatively stable and do not suffer from surge. This is because the pressure drop is in the same direction of the flow of the working fluid. Therefore there is no force to reverse the flow as in the compressor. The turbine model used here will actually be an algebraic function rather that a state-space differential model because the rotor dynamics are encompassed in the compressor model. Since the compressor and the turbine are directly coupled on the same shaft, the turbine speed is drawn from the compressor model. The latter uses the turbine torque to calculate the speed of the rotor based on the rotational momentum balance. The power developed by the turbine is calculated using the change in enthalpy in the working fluid

$$
P_{\text {turb }}=\eta_{t} \dot{m}_{\text {in }}\left(h_{\text {in }}-h_{\text {out }}\right)
$$

where

Pturb : total power developed by the turbine

$m_{\text {in }}$ : total mass flow rate into the turbine

$\eta_{t}$ : isentropic efficiency of turbine

$h_{\text {in }}$ : total specific enthalpy of the working fluid into the turbine

$h_{\text {out }}$ : total specific enthalpy of the working fluid out of the turbine based on ambient temperature

The torque developed by the turbine can be calculated from the turbine power and the angular velocity $\omega$ of the rotor from the compressor model.

$$
\tau_{t}=\frac{P_{\text {turb }}}{\omega}
$$

where $\tau_{t}$ is the total torque developed by the turbine. The net torque out of the gas turbine is calculated using the difference between $\tau_{t}$ e $\tau_{c}$.

$$
\tau_{\text {net }}=\tau_{t}-\tau_{c}
$$

where $\tau_{\text {net }}$ is the available torque to run the generator.

Therefore, the net power out of the gas turbine is:

$$
P_{\text {out }}=\tau_{n e t} \omega
$$

Figure 3 shows the turbine function created in the Simulink environment.

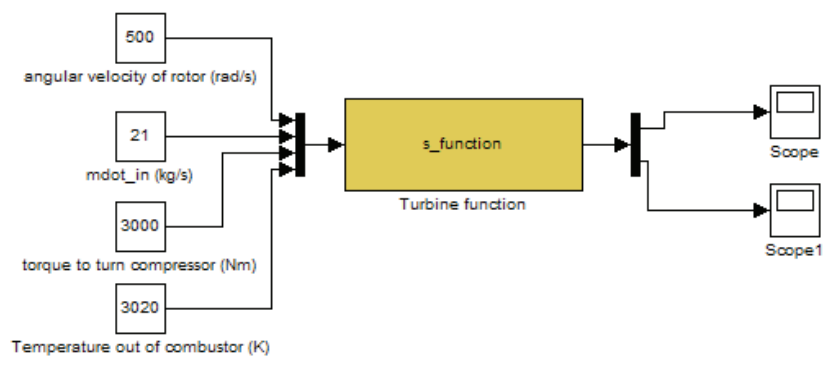

Fig. 3. Gas Turbine function.

\section{Modelling of Fuel Cells}

The mathematical modelling of the FC is a complex task and still need more investigation. The single components of the system interact with each other in a complex form, where the electrical, chemical, and thermodynamic processes are strongly non-linear in nature. These processes are accomplished at high efficiency, as the fuel cell has no moving parts. The parameters of such complex 
models are difficult to estimate. A model developed for dynamic power simulation of FCs available in the literature [9] has been used in this work as a starting point. The assumptions for the model are as follows.

- The gases are ideal

- The fuel cell is fed with hydrogen and air

- The pressure drop across the electrode channels is negligible

- The ratio of pressures between the inside and outside of the electrode channels is large enough to assume choked flow

- The fuel cell temperature is stable

- The Nerst equation applies

-The losses are as follows: Ohmic, Activation, Mass Transport.

The model development begins with the flow equation for choked flow:

$$
\frac{\dot{m}_{f_{c}}}{P_{u}}=K \sqrt{M}
$$

where

$\dot{m}_{f c}$ : mass flow rate

$K$ : valve constant

$P_{u}$ : upstream pressure (inside the electrode channels)

$M$ : fluid molar mass

$\dot{m}_{f c, H_{2}, \text { reacted }}$ : amount of hydrogen that reacts with the oxygen ions

$m_{f c, H_{2}, \text { in }}$ :amount of hydrogen entering the anode

A utilization factor $\left(U_{f}\right)$ is defined as the ratio of the amount of hydrogen that reacts with the oxygen to the amount of hydrogen entering the anode.

$$
U_{f}=\frac{\dot{m}_{f c, H_{2}, \text { reacted }}}{\dot{m}_{f c, H_{2}, \text { in }}}
$$

By considering that the molar flow of any gas through the valve is proportional to its partial pressure, the following equations are derived

$$
\frac{q_{\mathrm{H}_{2}}}{p_{\mathrm{H}_{2}}}=\frac{K_{a n}}{\sqrt{M_{\mathrm{H}_{2}}}}=K_{\mathrm{H}_{2}}, \frac{q_{\mathrm{H}_{2} \mathrm{O}}}{p_{\mathrm{H}_{2} \mathrm{O}}}=\frac{K_{a n}}{\sqrt{M_{\mathrm{H}_{2} \mathrm{O}}}}=K_{\mathrm{H}_{2} \mathrm{O}}
$$

where

$\mathrm{q}_{\mathrm{H} 2}, \mathrm{q}_{\mathrm{H} 2 \mathrm{O}}$ : molar flow rates of hydrogen and water, respectively

$\mathrm{p}_{\mathrm{H} 2}$, $\mathrm{p}_{\mathrm{H} 2 \mathrm{O}}$ : partial pressures of hydrogen and water, respectively

$\mathrm{K}_{\mathrm{an}}$ : valve constant of the anode

$\mathrm{K}_{\mathrm{H} 2}, \mathrm{~K}_{\mathrm{H} 2 \mathrm{O}}$ : valve molar constants for hydrogen and water, respectively

By substituting equations (6) and (7), equation (5) can be written as

$$
\frac{\dot{m}_{f c}}{p_{a n}}=K_{a n}\left[\left(1-U_{f}\right) \sqrt{M_{H_{2}}}+U_{f} \sqrt{M_{H_{2} O}}\right]
$$

being $p_{a n}$ the pressure inside the anode channel. The ideal gas law will be used to find the partial pressures of the gases flowing through the electrodes. This formula will be applied to all the gases. Only the expression for hydrogen is derived here

$$
p_{\mathrm{H}_{2}} V_{a n}=n_{\mathrm{H}_{2}} R T
$$

where

$\mathrm{T}$ : temperature

$\mathrm{V}_{\mathrm{an}}$ : volume of the anode channel

$\eta_{\mathrm{H} 2}$ : moles of hydrogen in the channel

R: ideal gas constant

By isolating the pressure and taking the first time derivative, one has

$$
\frac{d p_{H_{2}}}{d t}=\frac{R T q_{H_{2}}}{V_{a n}}
$$

The hydrogen flow can be subdivided into three parts, therefore equation (10) can be rewritten as follows

$$
\frac{d p_{H_{2}}}{d t}=\frac{R T}{V_{a n}}\left(q_{H_{2}}^{\text {in }}-q_{H_{2}}^{\text {out }}-q_{H_{2}}^{r}\right)
$$

where

$\mathrm{q}_{\mathrm{H} 2}{ }^{\text {in }}$ : molar flow rate of hydrogen into the channel

$\mathrm{q}_{\mathrm{H} 2}{ }^{\text {out }}$ : molar flow rate of hydrogen out of the channel $\mathrm{q}_{\mathrm{H} 2}{ }^{\mathrm{r}}$ : molar flow rate of hydrogen reacting in the channel

According to the electrochemical relationships, the amount of hydrogen that reacts can be calculated by

$$
q_{H_{2}}^{r}=\frac{N_{0} I}{2 F}=2 K_{r} I
$$

where

$\mathrm{N}_{0}$ : number of cells in the stack series

F: Faraday's constant

I: stack current

$\mathrm{K}_{\mathrm{r}}$ : modeling constant

By substituting equations (12) and (11) into equation (10), applying the Laplace transform, and isolating the partial pressure term, the following equation can be derived

$$
p_{H_{2}}=\frac{1 / K_{H_{2}}}{1+\tau_{H_{2}} s}\left(q_{H_{2}}^{i n}-2 K_{r} I\right)
$$

where

$\tau_{H 2}$ : the system pole associated with the hydrogen flow.

The stack output voltage is described by the Nerst equation [10]. The -rI term is the ohmic loss. This is the loss due to the resistance of the electrodes and to the resistance of the flow of $\mathrm{O}_{2}$ ions through the electrolyte. It yelds

$$
V=N_{0}\left[E_{0}+\frac{R T}{2 F}\left(\ln \frac{p_{\mathrm{H}_{2}} p_{\mathrm{O}_{2}}^{0.5}}{p_{\mathrm{H}_{2} \mathrm{O}}}\right)\right]-r I
$$


where

$\mathrm{V}$ : fuel cell output voltage

$\mathrm{E}_{0}$ : open cell voltage (based on the Gibbs free energy)

$\mathrm{R}$ : ohmic losses of the stack

The activation loss is caused by the sluggishness of the reactions at the electrode surfaces. A portion of the voltage is lost in driving the chemical reaction that moves the electrons to the electrodes. A way to account for these losses is to use the Tafel equation. This equation was derived by physical experimentation on various electrochemical reactions. It provides a relationship between the overvoltage at the surface of an electrode and the natural logarithm of the current density and can be used to calculate the activation voltage loss for the fuel cell [10]

$$
\Delta V_{a c t}=-A \ln (i)
$$

where

$\triangle V$ act : activation voltage loss

$A$ : slope of Tafel line (constant specific for SOFC)

$i$ : current density (current/electrode area)

Mass transport losses are due to the difference in concentration of the fuel as it passes through the electrode. The concentration will be high when the fuel and air enter the electrodes, but as they travel through, they get used up in the reaction. This concentration affects the partial pressure of the reactants and has an effect on the voltage that portion of the electrode can produce. Unfortunately this loss cannot be calculated analytically with enough accuracy. Therefore, experimental results are used to estimate the loss. Following equation (16) has been developed on an experimental basis and is accepted as a good approximation of the mass transport losses [10].

$$
\Delta V_{\text {trans }}=m \cdot e^{n i}
$$

where

AVtrans: voltage loss due to mass transfer and concentration loss

$m, n$ : constants derived from experiments (specific to SOFC and PEM)

Combining all the losses into equation (6), an equation for the overall voltage of a single FC can be obtained. In an actual FC power plant, multiple cells would be combined in series to provide the necessary voltage and current demand. The total stack voltage is

$$
V=N_{0}\left[E_{0}+\frac{R T}{2 F}\left(\ln \frac{p_{\mathrm{H}_{2}} p_{\mathrm{O}_{2}}^{0.5}}{p_{\mathrm{H}_{2} \mathrm{O}}}\right)\right]-r I-A \ln (i)+m e^{(n i)}
$$

The total power generated by the FC (PFC) is

$$
P_{F C}=N_{0} V I
$$

The complete FC Simulink scheme is shown in Fig. 4.

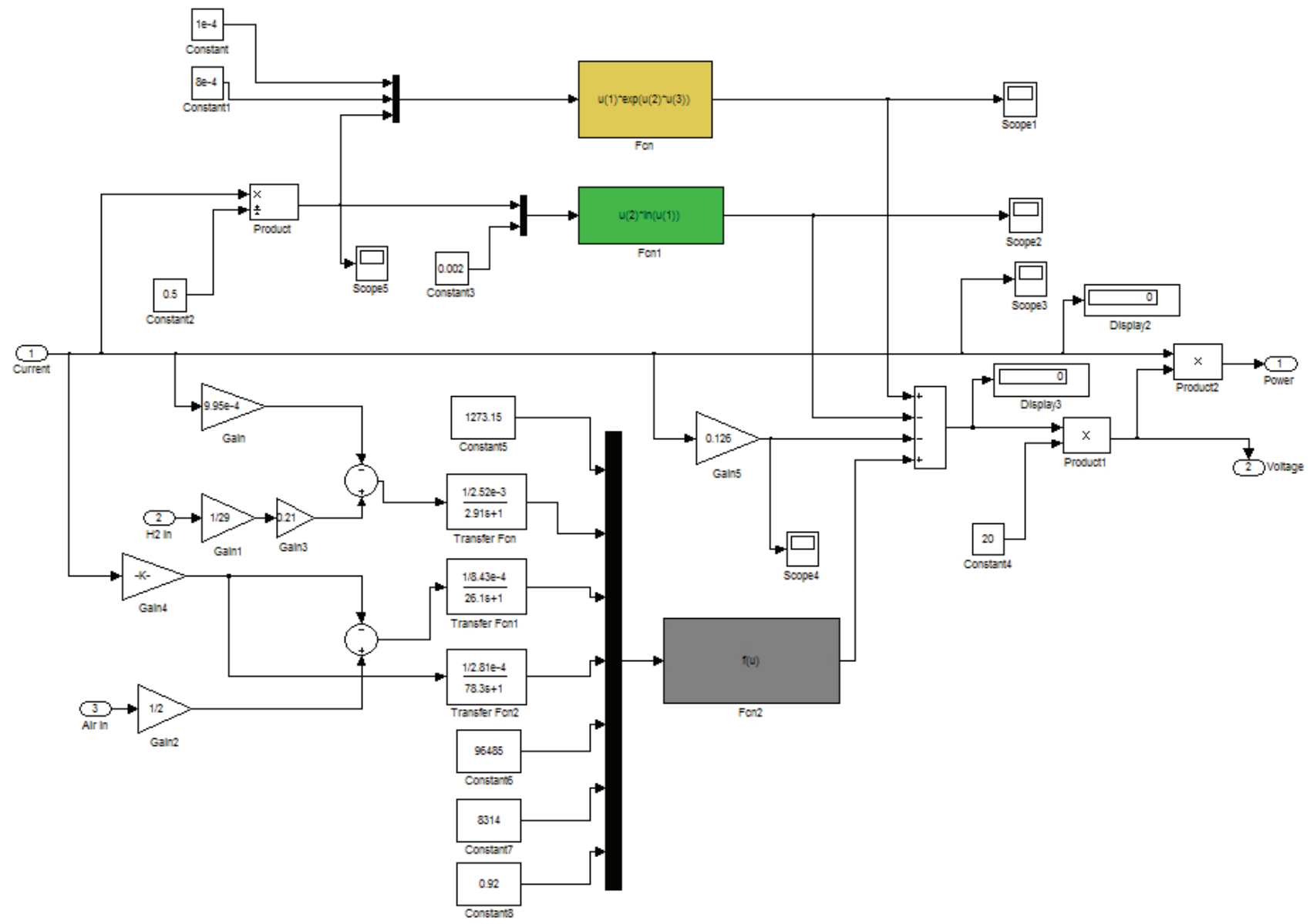

Fig. 4. Fuel cell Simulink scheme. 
The model has been validated by means of an experimental prototype built by an Italian research company; the model has been used to simulate and predict the behaviour of a $200 \mathrm{~kW} \mathrm{SOFC} \mathrm{system.} \mathrm{Fig.} 5$ shows a picture of a prototype stack. The model was run using parameters given by the company and summarized in Table II.

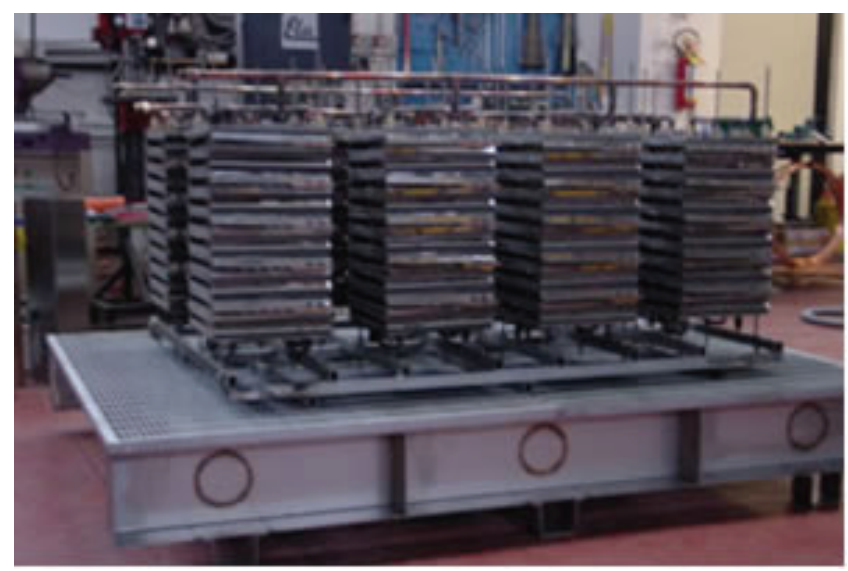

Fig. 5. SOFC prototype.

TABLE II. SOFC Simulation Parameters.

\begin{tabular}{|c|c|}
\hline \hline Symbol & Quantity \\
\hline $\mathrm{K}_{\mathrm{r}}$ & $9.95 \mathrm{e}-4$ \\
\hline $\mathrm{FC}_{\mathrm{Temp}}$ & $1273.15 \mathrm{~K}$ \\
\hline $\mathrm{Kmol} / \mathrm{Kg}$ air & $1 / 29$ \\
\hline $\mathrm{Kmol} / \mathrm{Kg} \mathrm{H} \mathrm{H}_{2}$ & $1 / 2$ \\
\hline $\mathrm{No}_{\mathrm{H} 2}$ & 20 \\
\hline $\mathrm{K}_{\mathrm{H} 2 \mathrm{O}}$ & $2.43 \mathrm{e}-4 \mathrm{kmol}(\mathrm{atm} \mathrm{s})$ \\
\hline $\mathrm{K}_{\mathrm{O} 2}$ & $2.52 \mathrm{e}-3 \mathrm{kmol}(\mathrm{atm} \mathrm{s})$ \\
\hline$\tau_{\mathrm{H} 2}$ & $26.1 \mathrm{~s}$ \\
\hline$\tau_{\mathrm{H} 2 \mathrm{O}}$ & $78.3 \mathrm{~s}$ \\
\hline$\tau_{\mathrm{O} 2}$ & $2.91 \mathrm{~s}$ \\
\hline $\mathrm{r}$ & $0.126 \mathrm{ohm}$ \\
\hline
\end{tabular}

Figures 6 shows the power outputs of the model. The initial transients are due to the start-up of the model, the initial conditions of the transfer functions being zero. It can be seen that the fuel cell produces approximately $200 \mathrm{~kW}$ of power with a 300 A current demand at steady state. 20 fuel cells connected in series are modeled.

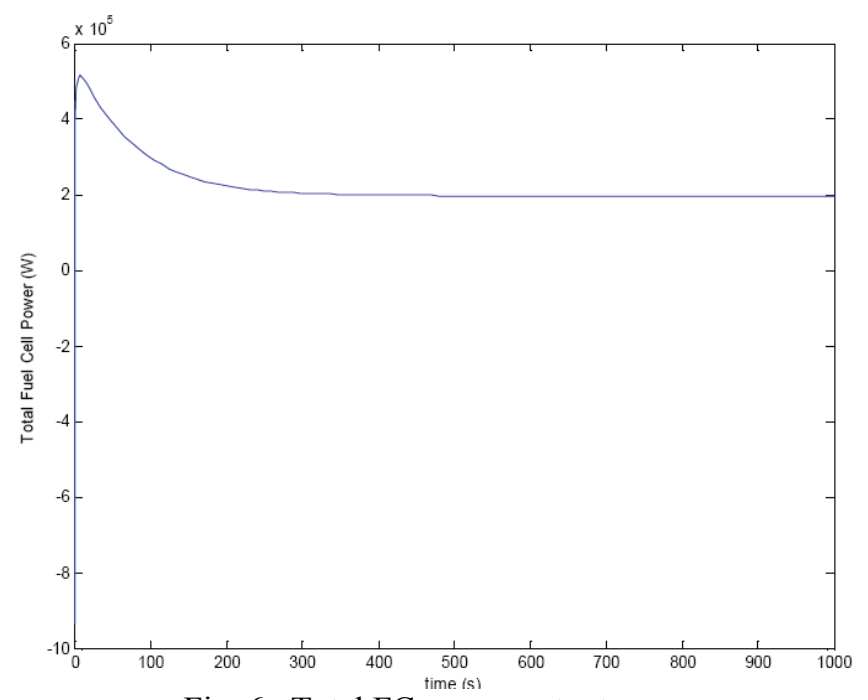

Fig. 6. Total FC power output.

\section{Model integration}

The realized models can be integrated into a number of combinations of IFCGT power plants. The basic idea is to combine them in such a way that the high temperature of the fuel cell exhaust gas is exploited to run the gas turbine. This can be accomplished using heat exchangers to transfer energy from one stream to another. Two plant configurations have been developed and simulated. In one case the FC exhaust gas flows through a heat exchanger and heats the TG working fluid; in the second case the FC air input is supplied through a heat exchanger in which the TG exhaust gas releases a part of its heat content. The two configurations have been analysed with respect to dynamic phenomena and basic control techniques have been used to control various parameters. It has come out that the system can be controlled through the FC hydrogen flow rate and the $\mathrm{TG}$ inlet temperature. In the first configuration (Fig.7) the FC operates independently and a heat exchanger is used to transfer heat from the FC exhaust to the working fluid of the GT coming from the compressor. This eliminates the need for a combustor to raise the temperature of the working fluid before entering the turbine. Separating the working fluids of the FC and the GT has the advantage that the pressure fluctuations in the gas turbine do not affect the pressure of the FC.

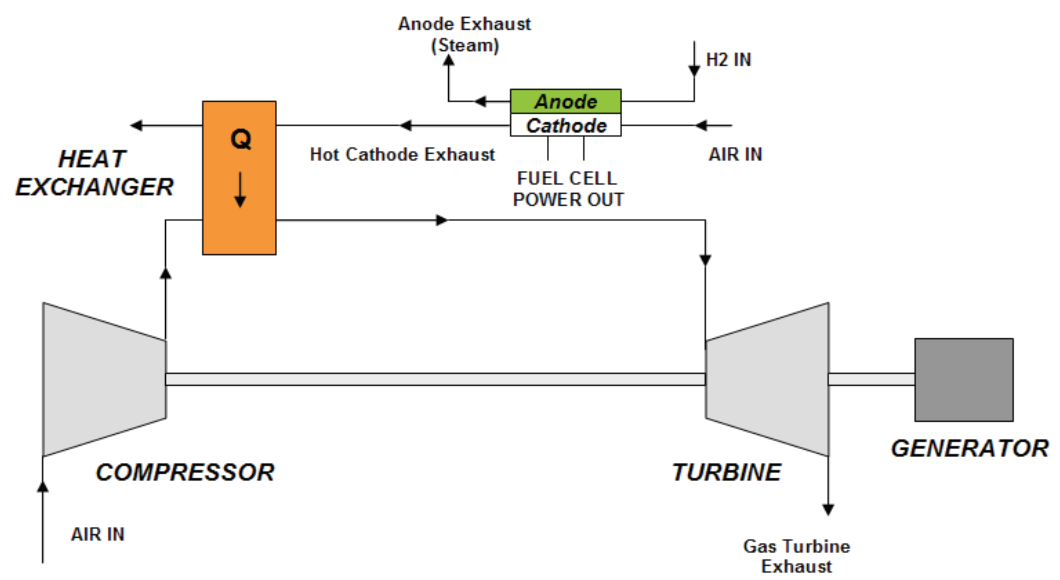

Fig. 7. First IFCGT configuration. 
As previously stated, the mismatched dynamics of the gas turbine and the fuel cell will produce combined transients in the output power of the entire power plant. These transients will be evident during startup and shutdown of the system as well as transients in power demand of the grid. The results of simulations in these conditions are reported in Figures $8-11$. The fuel cell power stabilizes at approximately $200 \mathrm{~kW}$ and the gas turbine stabilizes at approximately $70 \mathrm{~kW}$, yielding a total plant power of $270 \mathrm{~kW}$.

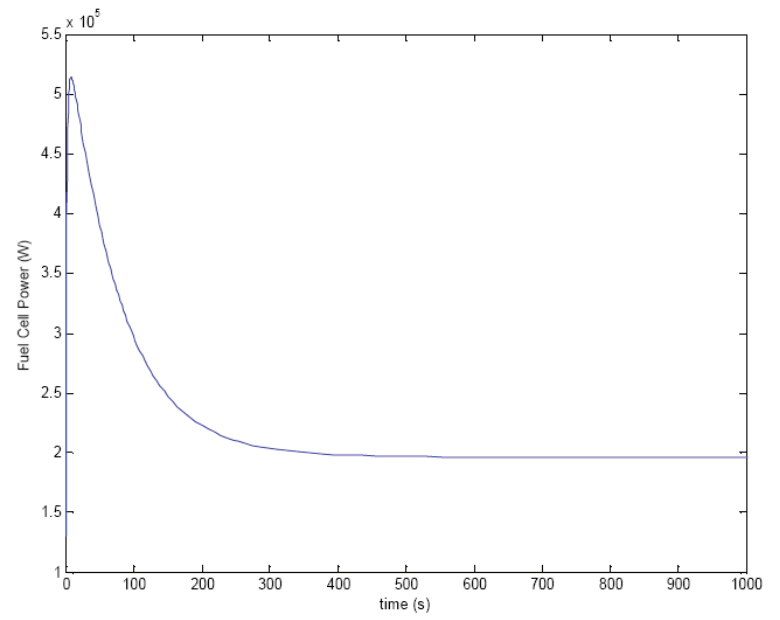

Fig. 8. Fuel cell power.

It can be seen from Figure 8 that the fuel cell stabilizes at approximately 60 times faster (400 s) than the gas turbine $(25,000 \mathrm{~s})$ response shown in Figure 9. The velocity of the gas turbine rotor shown in Figure 10 is slow to reach a steady state condition due to the inertia of the turbine and compressor. It stabilizes at approximately $188 \mathrm{rad} / \mathrm{s}$, which is equivalent to $1800 \mathrm{rpm}$. As seen from Figure 11, the convergence of the total plant power output is dominated by the turbine response, which has the slowest dynamics.

In the second configuration (Fig. 1) the working fluid from the compressor flows directly through the cathode of the FC. The output from the cathode, as well as the leftover fuel from the anode is combusted and run through the turbine. The TG exhaust gas is then used to pre-heat the compressed air before it enters the cathode of the fuel cell.

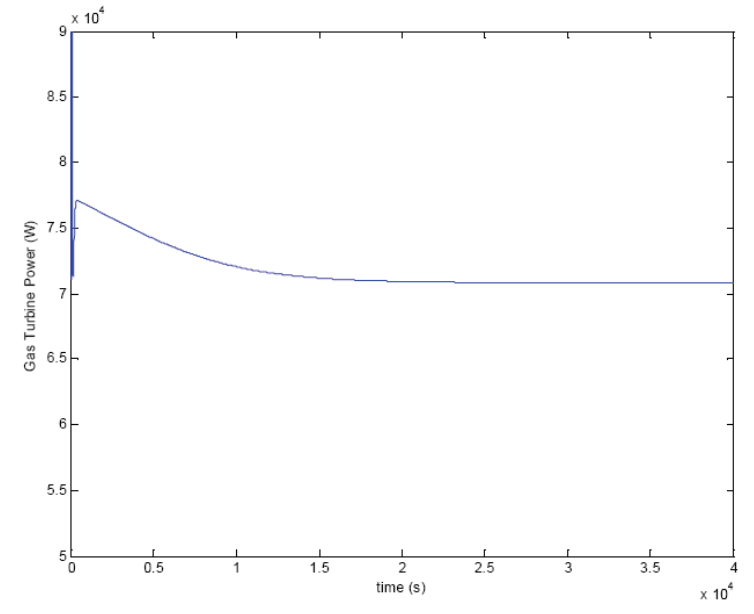

Fig. 9. Gas Turbine power.

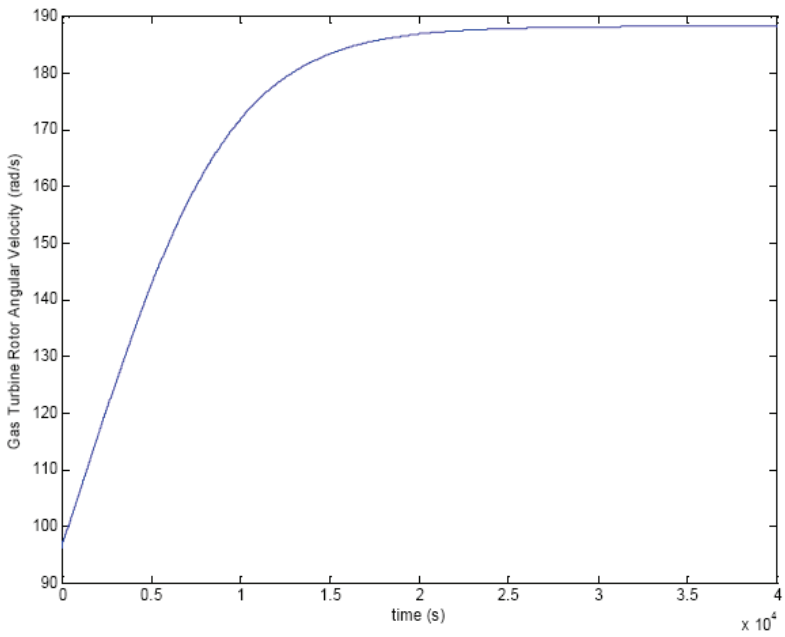

Fig. 10. Gas Turbine Rotor angular velocity.

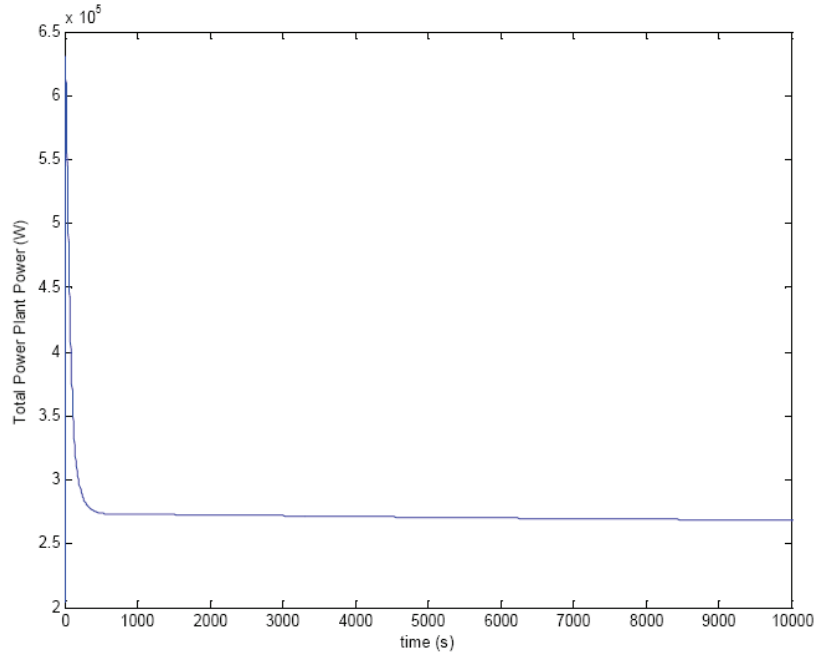

Fig. 11. Total plant power.

The dynamic mismatch between the GT and the FC causes combined transients in the output power of the plant. These transients are evident during startups and shutdowns of the system as well as transients in power demand of the grid. The heat exchanger model is excluded due to the fuel cell temperature assumed to be constant. Figures 12-15 show the results of running this model. The FC power is $470 \mathrm{~kW}$ while the GT power is $430 \mathrm{~kW}$. In this case the GT contributes with much more power because excess fuel is combusted in the working fluid before it expands through the turbine. The fluid exits the fuel cell at approximately $1300 \mathrm{~K}$ and is combusted to a temperature of $3000 \mathrm{~K}$. Therefore, the fluid has a much higher enthalpy than in the previous configuration. The total power for the entire power plant is $900 \mathrm{~kW}$.

Figure 12 shows that the fuel cell power reaches the steady state in approximately $7 \mathrm{~s}$. This time is shorter than the previous configuration due to the additional mass flow rate of the air delivered to the FC by the compressor. Figure 13 shows the GT power. As expected, the stabilization time is higher than that of the FC.

The two hybrid configurations were simulated with respect to dynamic inputs. This consisted of stepping various inputs to determine the effect on the system outputs. It comes out that varying the $\mathrm{H}_{2}$ input flow rate on the FC has an impact on the total plant power as well 
as the gas turbine power and rotor velocity. Therefore, this input could possibly be used to control the output power of the plant. A separate control mechanism was implemented to control the rotor velocity - and hence the power - of the gas turbine. This consisted of injecting temperature controlled air into the working fluid stream just before the turbine. This would control the inlet temperature of the turbine as well as the enthalpy of the inlet fluid. Since the power generated by the turbine is directly proportional to the change in enthalpy of the working fluid, the output power and the rotor velocity of the gas turbine can be controlled.

This scenario was implemented on the hybrid model using a PID controller. After some tweaking of the PID gains it was found that the angular velocity of the GT could be controlled with respect to an input set point using the air inject method. The control analysis performed in this study is not intended to be exhaustive, but rather to give a preliminary look at possible control methods. Figure 16 shows the response of the deviation of the FCower due to a small change in the angular velocity of the GT rotor. It is observed that the fuel cell power does vary slightly with respect to rotor velocity. Therefore the angular velocity of the rotor could possibly be used as a control for the output power of the FC and the GT.

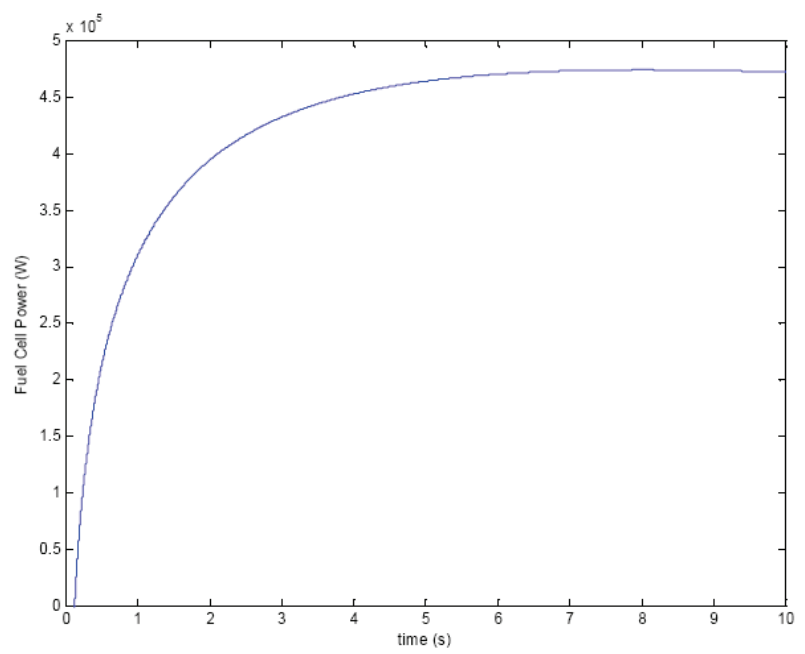

Fig. 12. Fuel Cell power.

\section{Conclusions}

Models for the various components of a FC - GT hybrid system have been developed using MATLAB and Simulink software. The component models are an axial flow compressor, a combustor, a turbine, a heat exchanger, and a solid oxide FC. Each component model was developed and validated independently before integration into the complete system. Two hybrid configurations were simulated to analyse the general plant behaviour in terms of power, rotor velocity, and fuel cell voltage.

This flexible modular tool can be used to form a great variety of hybrid power plant combinations. The main achievement of this study is the development of modular models that can be used for future research. Additional components could be used to better simulate a FCGT hybrid plant. For example, a fuel reformer could be integrated into the FC model. This would represent an actual FC cycle more accurately. Also, a humidifier could be attached to the FC. Valve dynamics could also be included to better simulate the air inject and $\mathrm{H}_{2}$ input flow controls.

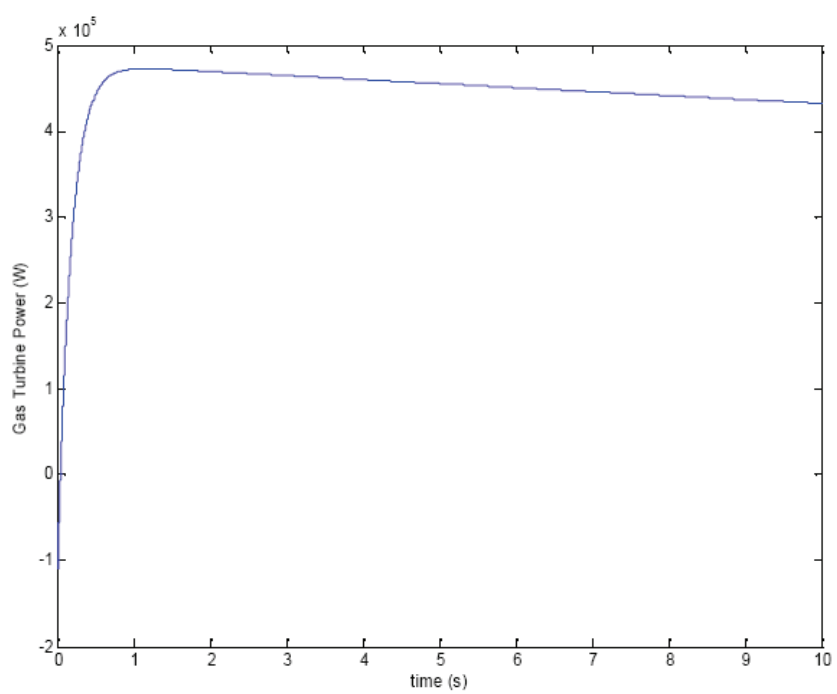

Fig. 13. Gas Turbine power.

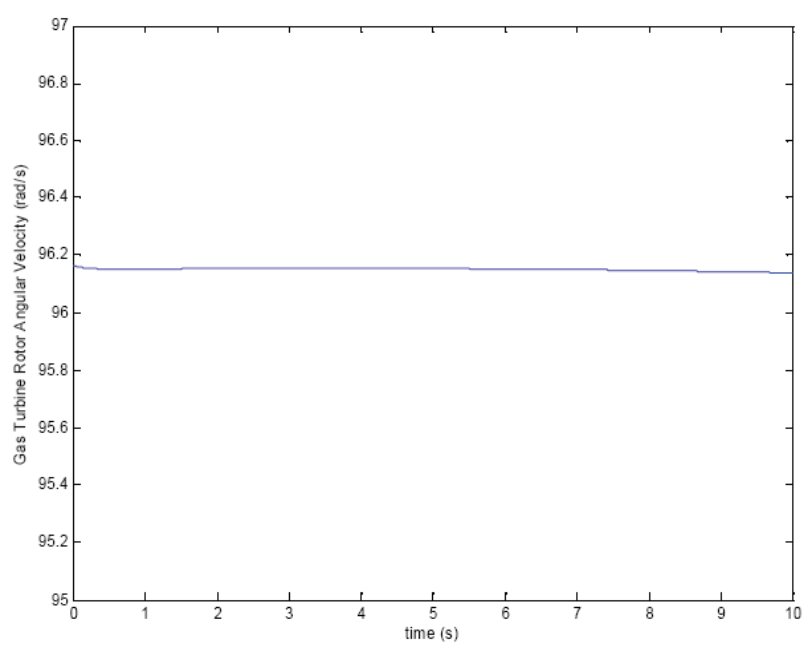

Fig. 14. Gas Turbine Rotor angular velocity.

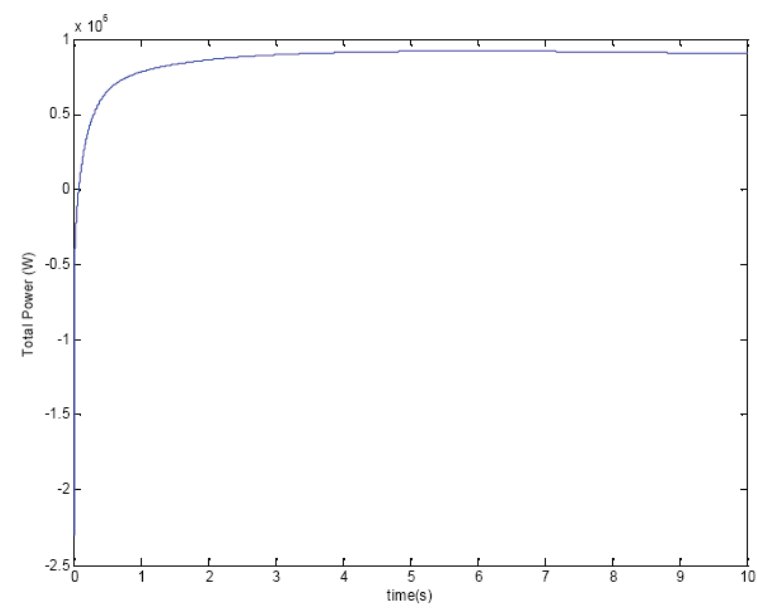

Fig. 15. Total plant power. 


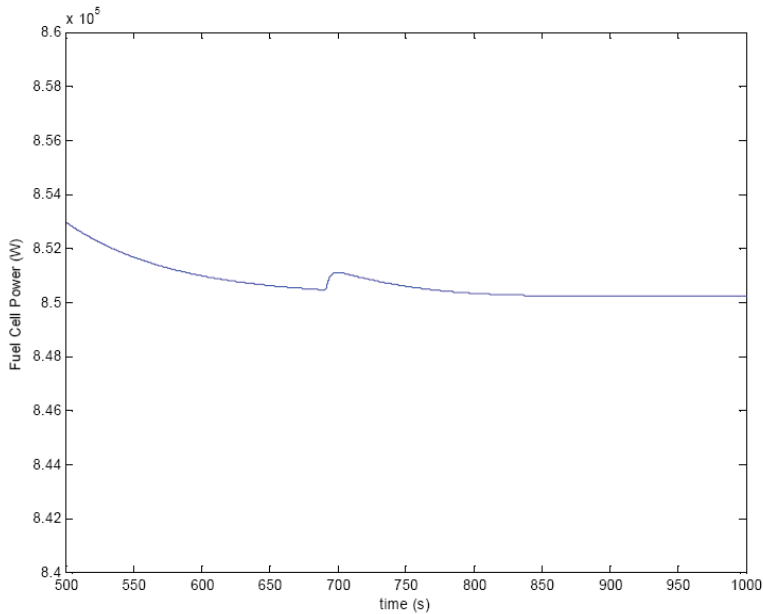

Fig. 16. Fuel Cell Power Reaction to Step in Rotor Angular Velocity.

\section{References}

[1] C.Boccaletti, G. Di Grazia, G.Fabbri, E. Nisticò, Energy models for stand alone power systems, EETI - 5th Int. Conf. on Energy, Environment and Technological Innovation, Rio de Janeiro, Brazil, 2004

[2] C. Boccaletti, S. Elia, E. Nisticò, L. Petrucci, A model of a hybrid wind-photovoltaic stand alone generator, ENER'05 - Int. Conf. on Renewable Energies and Environment, Figueira da Foz (Portugal), 2005
[3] G.Fabbri, E. Nisticò, E.Santini, Building Simulation Modeling Environments, 5th WSEAS Int. Conf. on Power Systems and Electromagnetic Compatibility, Corfu (Greece), 2005

[4] C. Boccaletti, G. Duni, G. Fabbri, E. Santini, Simulation Models of Fuel Cell Systems, ICEM 2006 17th Int. Conf. on Electrical Machines, Chania (Greece), 2006

[5] C. Boccaletti, G. Fabbri, E. Santini, A Tool for the Simulation of Integrated Renewable Energy-Fuel Cell Systems, ENER'06 - Int. Conf. on Renew. Enrgs and Env., Figueira da Foz (Portugal), 2006

[6] C. Boccaletti, S. Elia, E. Nisticò - "A Dynamical Model of a Gas Microturbine Generator for Distributed Generation", Atti dell'EUROPES 2005 - 5th International Conference on Power and Energy Systems, Benalmàdena (Spagna), 15-17 giugno 2005

[7] O.A. Asbjǿrnsen, Systems Modeling and Simulation, SKARPODD Co., Maryland 1992

[8] H. Cohen, G. F. C. Rogers, H. I. H. Saravanamuttoo. Gas Turbine Theory. John Wiley and Sons, Inc., New York, NY, 1973.

[9] Padulles J., Ault G. W., McDonald J. R. “An Integrated SOFC Plant Dynamic Model for Power Systems Simulation", Journal of Power Sources, volume 86, p. 495, 2000.

[10] Larminie J., Dicks A., "Fuel Cell Systems Explained" John Wiley and Sons, Inc., New York, NY, 2003. 